\title{
Investigation on the Microstructure of Direct Laser Additive Manufactured Ti6Al4V Alloy
}

\author{
Yuanfei Han ${ }^{a, b *}$, Weijie Lu ${ }^{a}$, Tom Jarvis ${ }^{b}$, John Shurvinton ${ }^{b}$, Xinhua $W^{b}$ \\ ${ }^{a}$ State Key Laboratory of Metal Matrix Composite, Shanghai Jiao Tong University, \\ Shanghai, 200240, PR China \\ ${ }^{b} A R C$ Centre of Excellence for Design in Light Metals, Monash University, Clayton, Victoria, Australia
}

Received: September 1, 2014; Revised: October 21, 2015

\begin{abstract}
Direct laser fabrication (DLF) is one of the advanced near-net shape processing technologies. The variations of laser parameters can change the energy distribution within a laser scan, and thus affect the cooling rate, and resulting microstructure of deposited material. In this study, the effect of the laser parameters on the microstructure of additive laser fabricated Ti6Al4V alloy was investigated. It was found that huge columnar grains formed during laser fabrication of Ti6Al4V alloy for a wide range of processing conditions, and the laser power, scanning speed and duration time were had a significant effect on the refinement of the prior grains. Gradient morphologies were obtained from a complex thermal history.
\end{abstract}

Keywords: direct laser fabrication, Ti6Al4V alloy, columnar grain, equiaxed grain, additive manufacturing

\section{Introduction}

Additive manufacturing is a relative novel idea to fabricate complex, net-shaped metal components in successive layers ${ }^{1}$. Direct laser deposition is one of the additive manufacturing techniques for metals which are currently under investigation ${ }^{2}$. In this method, the shaped part is produced using a CAD file to move the nozzle in the XY-plane and the powder feed in three angles to Z-direction to add successive layers. Recently, a lot of studies have been done on the direct laser deposition which showed the significant effect of the laser parameters such as laser powder, scanning speed and duration time, etc ${ }^{3-8}$. Kruth et al. ${ }^{3}$ studied the processing window, including the selection of appropriate scan patterns, for a mixture of different types of metal powder particles. It was found that intermediate range parameters produced sufficient remelting of the previous layer. Yadroitsev et al. ${ }^{4}$ studied the effect of laser power and scanning speed on the profile of melted or deposited lines of Inox904L steel powder using Phoenix machine, and it was found that $120 \mu \mathrm{m}$ was the optimum hatch distance in terms of porosity, and little difference was found in the tensile properties of the samples. Nowadays, there are several reports published regarding additive manufacturing of metals using powder, e.g. those from the Monash University ${ }^{5}$, University of Birmingham ${ }^{6-8}$, Northwestern Polytechnical University 9 , Beihang University ${ }^{10}$ and NASA Langley Research Center ${ }^{11}$, etc. From these previously reported papers, it could be seen that these studies are mainly concentrated with the equipment, the laser software and the relationship between single laser parameter and the properties of materials. More work is still required to understand the microstructure development during the direct laser process and the relationship between the

*e-mail: hyuf1@hotmail.com

process parameters and the microstructure of the deposited parts. In this paper, a powder-feed laser based process was used for the manufacture of Ti6Al4V samples. The effect of laser deposition parameters on the microstructure of additive layer manufactured Ti6Al4V was investigated.

\section{Experimental}

The materials used in this study are Ti6Al4V powder particles with size of 100 200 $\mu \mathrm{m}$ in diameter. $5 \mathrm{~mm}$ thin plate was used as a substrate, which was cut from cast Ti6Al4V block using electrical discharge machining (EDM) machine. The surface was ground with 320 grit $\mathrm{SiC}$ paper, and cleaned with ethanol before the deposition. A TRUMPF DLD (blown powder) system fitted with $4 \mathrm{KW}$ disc laser has been used to fabricate Ti6Al4V samples. The spacing between the nozzle tip and the substrate was set up as $16 \mathrm{~mm}$ which will give rise to certain build layer thickness for specific sample. Thin wall Ti6Al4V samples of $20 \mathrm{~mm}$ in length, $10 \mathrm{~mm}$ in height and $4 \mathrm{~mm}$ in thickness are built by multilayer deposition in this study. The deposition process was carried out in an argon atmosphere with $\mathrm{O}_{2}<20 \mathrm{ppm}$, titanium powders were fed through three beam nozzles into the laser focus point. The laser fabrication parameters used in this study are listed in Table 1. The Z-incensement is $0.12 \mathrm{~mm}$ in all the samples examined in this paper. Samples with different parameters are cut along longitudinal direction including the Ti6A14V substrate. All the samples were ground, polished and etched for optical observation. The effect of the laser power, scanning speed and duration time on microstructure of Ti6Al4V thin wall samples were investigated individually. Figure 1 shows the experiment process and the examples of different shaped components. 
Table 1. Parameters used for deposition of Ti6Al4V thin wall samples.

\begin{tabular}{ccccc}
\hline No & Peak laser power/(W) & Pulse duration/(s) & Frequency/(Hz) & Scan speed/(mm/min) \\
\hline $\mathbf{1}$ & 1538 & 1.3 & 500 & 800 \\
$\mathbf{2}$ & 1230 & 1.3 & 500 & 800 \\
$\mathbf{3}$ & 923 & 1.3 & 500 & 800 \\
$\mathbf{4}$ & 2000 & 0.6 & 500 & 800 \\
$\mathbf{5}$ & 2000 & 0.9 & 500 & 800 \\
$\mathbf{6}$ & 3000 & 0.3 & 1000 & 800 \\
$\mathbf{7}$ & 3000 & 0.3 & 500 & 800 \\
$\mathbf{8}$ & 4000 & 0.3 & 500 & 800 \\
$\mathbf{9}$ & 1538 & 0.6 & 500 & 800 \\
$\mathbf{1 0}$ & 2000 & 0.3 & 1000 & 800 \\
$\mathbf{1 1}$ & 923 & 1.3 & 500 & 1200 \\
$\mathbf{1 2}$ & 923 & 1.3 & 500 & 600 \\
\hline
\end{tabular}

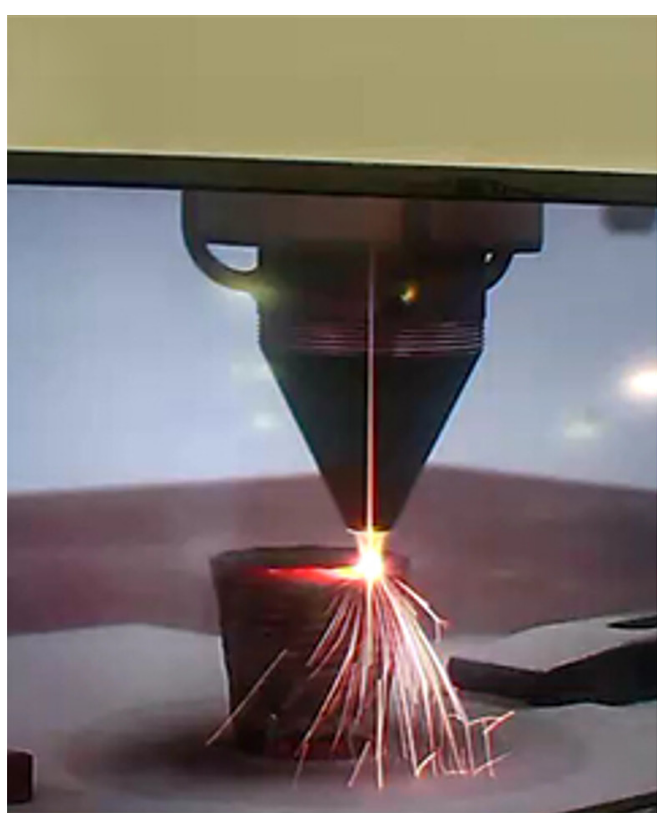

(a)

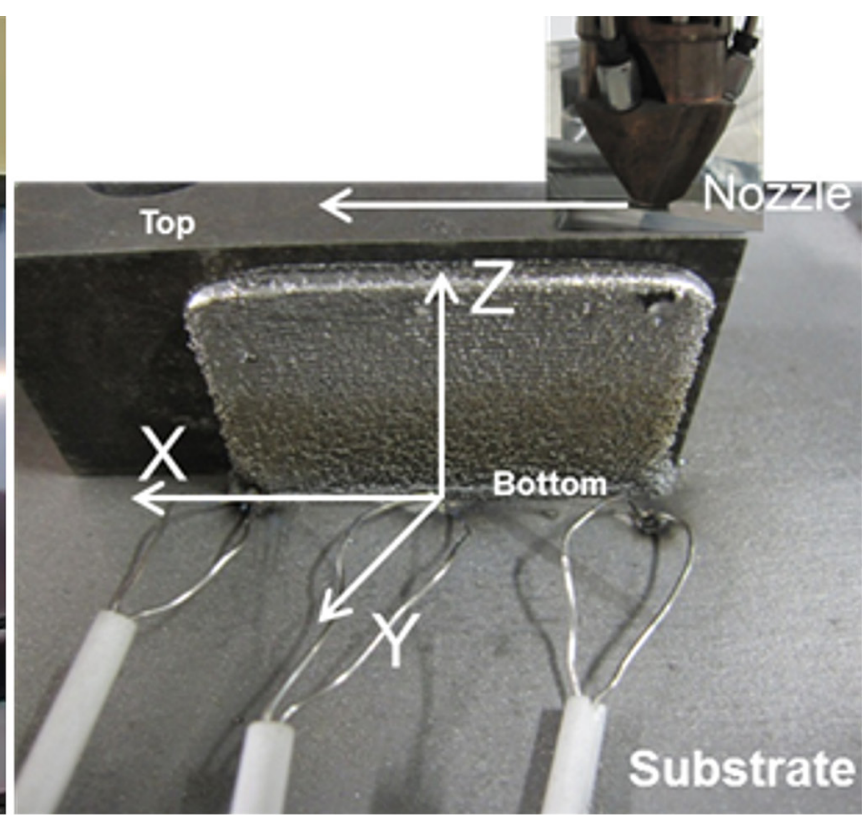

(b)

Figure 1. The experiment process and the examples of different shaped components (a) cylinder (b) thin wall.

\section{Results}

\subsection{Effect of laser power}

Figure 2 shows the macrostructure of the pulse laser fabricated Ti6Al4V alloy, which was obtained at various laser powers ( $923 \mathrm{~W}, 1230 \mathrm{~W}$ and $1538 \mathrm{~W})$. All macrographs are shown in longitudinal direction, it should be noted that this alloy tends to form large columnar growth prior $\beta$ grains under most laser deposition process. The morphology of $\beta$ grain has been changed obviously with increasing the laser power, the size of the columnar grains in individual samples varies from the edge to the center and from the bottom to the top (Figure 1a). By increasing the laser power, the length of the columnar grains becomes shorter, and the equiaxied grain also has been obtained. Although a few small equiaxed grains obtained at the bottom of the sample built with a power of $1538 \mathrm{~W}$, the height of this region is normally less than $2 \mathrm{~mm}$. It is also noted that samples cannot be built with a very high laser power ( $>1538 \mathrm{~W})$. For example, a sample fabricated with laser power of $1538 \mathrm{~W}$, the defined sample height is $10 \mathrm{~mm}$ and Z-increment is $0.12 \mathrm{~mm}$, but the actual height obtained is only $7 \mathrm{~mm}$.

\subsection{Effect of laser scanning speed}

Figure 3 shows the effect of laser scanning speed on the grain microstructure of the laser built sample. The experiment were conducted at the same heat input conditions, it means keeping frequency, laser power and other laser parameters constant to guarantee the input energy. It can be clearly seen that for a given laser power and frequency, the huge columnar grains became broadened with an increase of laser scanning speed. The maximum grain width could reach $2.5 \mathrm{~mm}$. It was also noted that the morphology of the prior $\beta$ grains has no significant difference with those samples deposited at slow scanning speed, and there are some layer bands in all examined samples. The thickness of the layer band normally reduced 


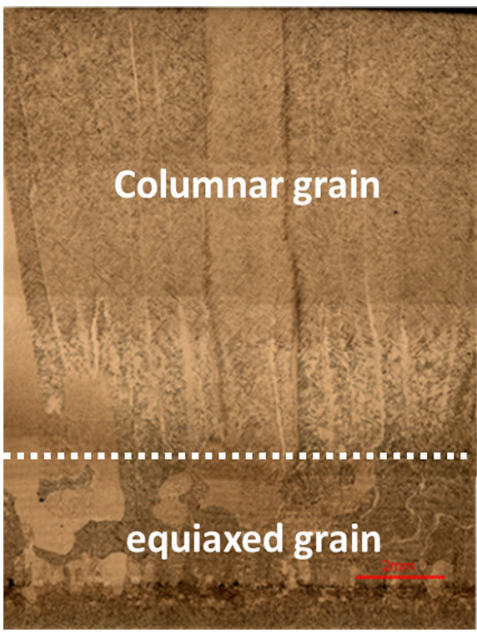

(a)

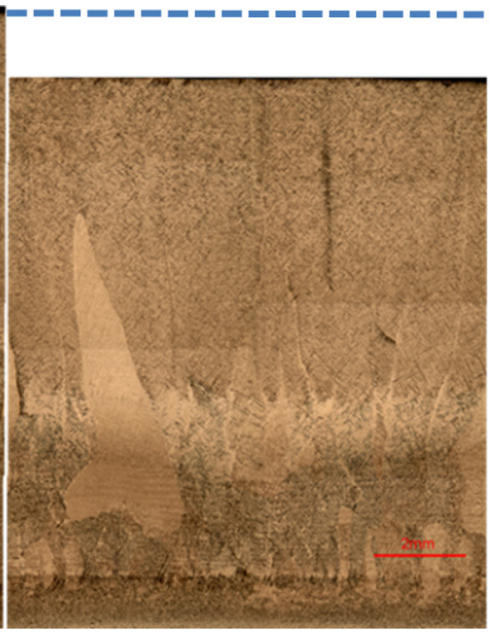

(b)

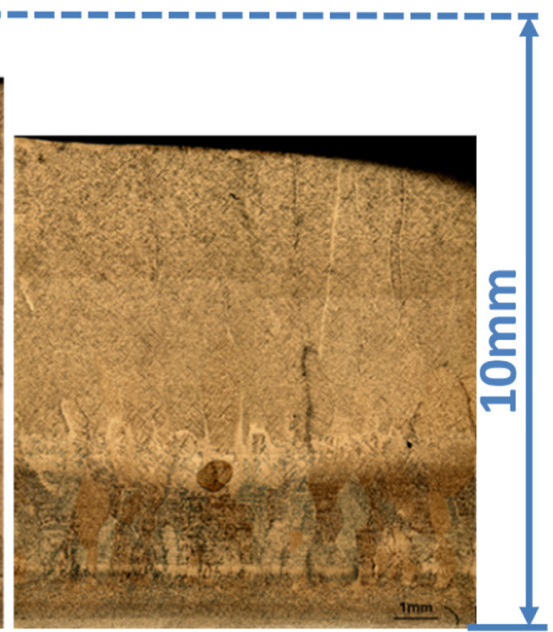

(c)

Figure 2. Montage of macrostructure of pulse laser deposition Ti6Al4V thin wall showing large columnar growth prior $\beta$ grains with laser power of $923 \mathrm{~W}$ (a); $1230 \mathrm{~W}$ (b); $1538 \mathrm{~W}$ (c). (Frequency is $500 \mathrm{HZ}$, scanning speed is $800 \mathrm{~mm} / \mathrm{min}$, and average laser power is $600 \mathrm{~W}(\mathrm{a}) ; 800 \mathrm{~W}(\mathrm{~b}) ; 1000 \mathrm{~W}(\mathrm{c}))$.

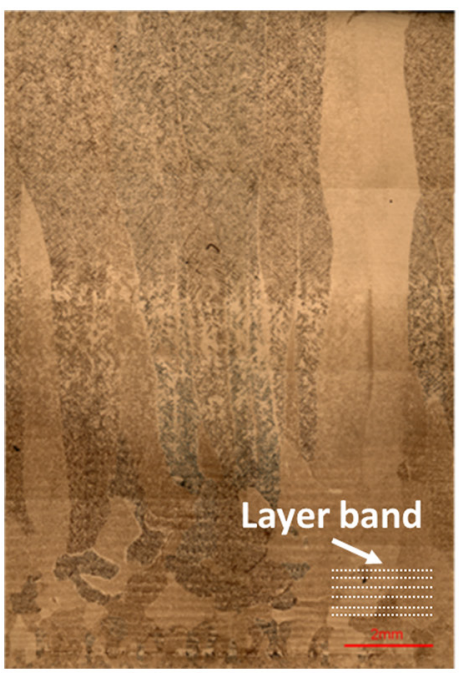

(a)

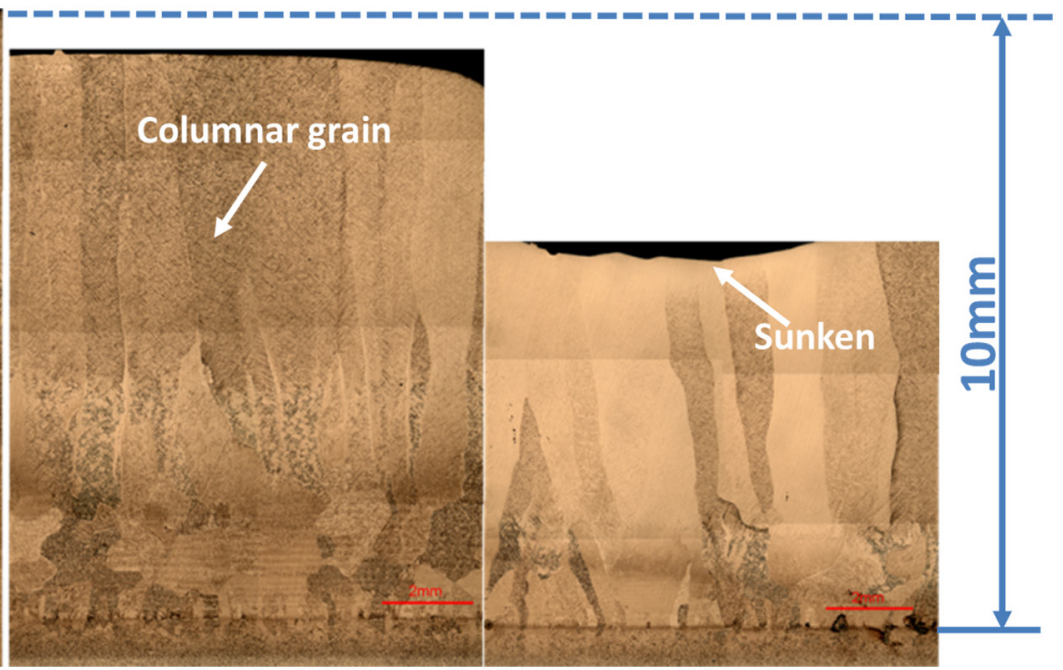

(b)

(c)

Figure 3. Montage of macrostructure of pulse laser deposition Ti6Al4V thin wall showing large columnar growth prior $\beta$ grains with scanning speed of $600 \mathrm{~mm} / \mathrm{min}$ (a); $800 \mathrm{~mm} / \mathrm{min}$ (b); $1200 \mathrm{~mm} / \mathrm{min}$ (c). (Frequency is $500 \mathrm{HZ}$, laser power is $923 \mathrm{~W}$, and average laser power is $600 \mathrm{~W}$ ).

and gradually disappeared at the top of the samples. It also decreased with the increasing scanning speed (Figure 3c). Moreover, it is difficult to build a defined size sample when the scanning speed is much higher $(>1200 \mathrm{~mm} / \mathrm{min})$. The actual height of the sample was only approximately $5 \mathrm{~mm}$ at scanning speed of $1200 \mathrm{~mm} / \mathrm{min}$ (Figure 3c).

\subsection{Effect of laser duration time}

In order to investigate the macrostructure affected by the pulse duration time, short and long duration time are used to deposit samples at laser power of $2000 \mathrm{~W}$, keeping the frequency of $500 \mathrm{~Hz}$ and the scanning speed of $800 \mathrm{~mm} / \mathrm{min}$. The samples deposited at different duration time are shown in Figure 4. Figure $4 \mathrm{a}, \mathrm{b}$ are deposited for $0.6 \mathrm{~s}$ and $0.9 \mathrm{~s}$, respectively. It was found that the duration time had great effect on the prior $\beta$ grains. Huge columnar grains were observed with both short and long duration time. With an increase of duration time from $0.6 \mathrm{~s}$ to $0.9 \mathrm{~s}$, the huge columnar grains became shorter and smaller, and the height of the build was lower than the sample built at short duration time.

\section{Discussion}

During the direct laser fabricated process of Ti6Al4V alloy thin wall, it is found that the huge columnar grains are easily obtained. We have not found any effective method to achieve grain refinement by changing the laser deposition parameters. There are only a few smaller equiaxed grains 


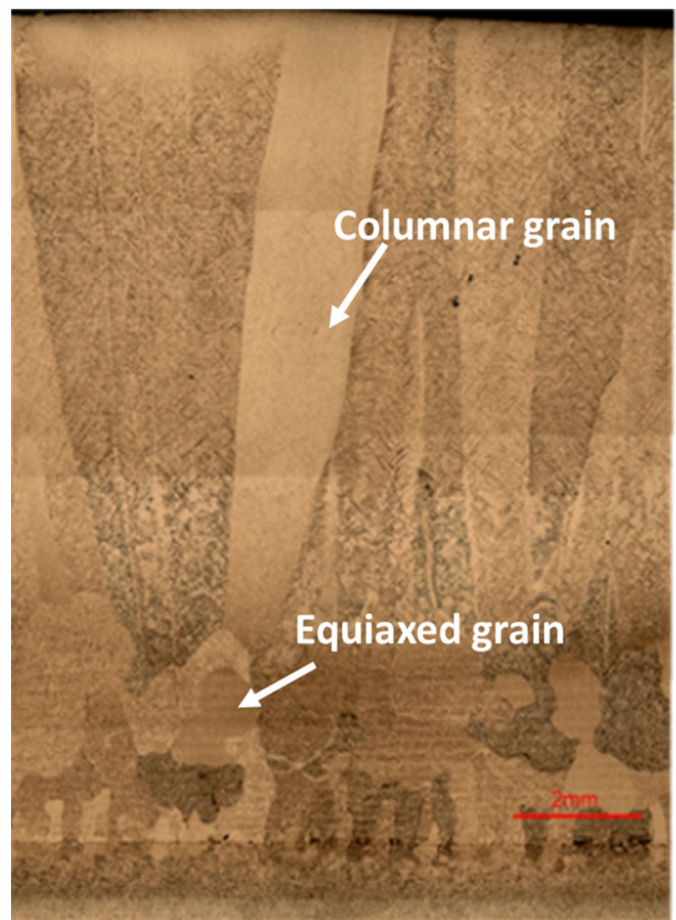

(a)

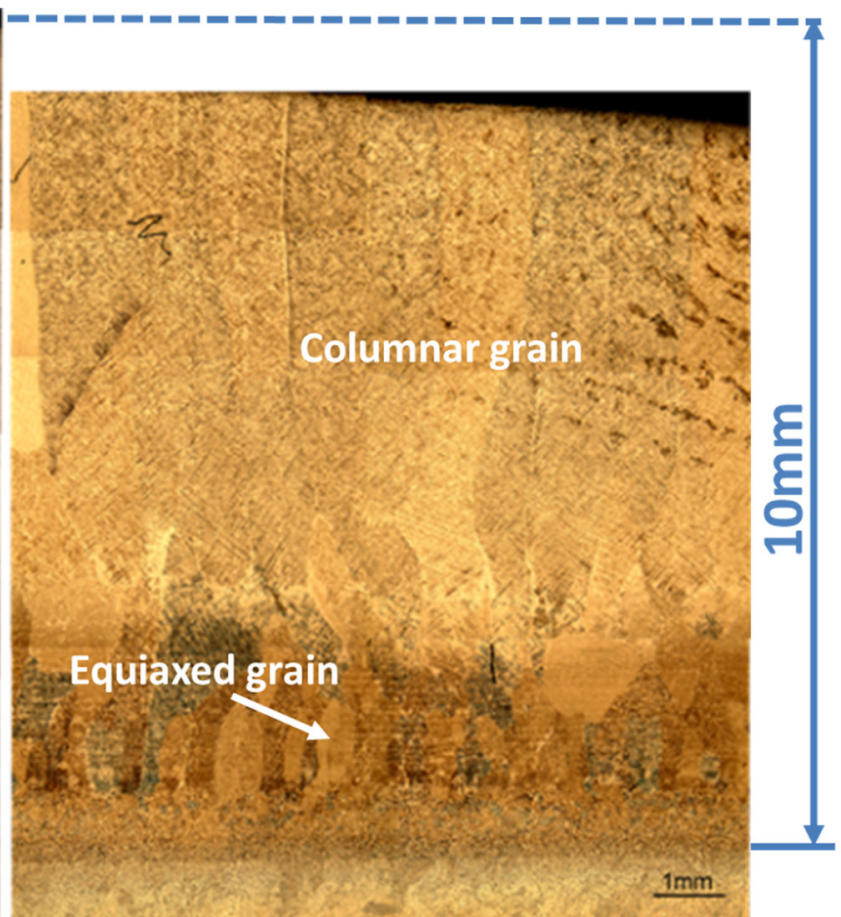

(b)

Figure 4. Montage of macrostructure of pulse laser deposition Ti6Al4V thin wall showing large columnar growth prior $\beta$ grains with duration time of $0.6 \mathrm{~s}(\mathrm{a}) ; 0.9 \mathrm{~s}$ (b). (Frequency is $500 \mathrm{HZ}$, scanning speed is $800 \mathrm{~mm} / \mathrm{min}$, and average laser power is $600 \mathrm{~W}$ (a); $900 \mathrm{~W}$ (b)).

which could be found at the bottom of the deposit. The reason should be related to the higher cooling rate. Once the laser passes the Ti6A14V substrate, the Ti6A14V substrate should be heated up to the liquids temperature in the heat affect zone, some small equiaxed grains could grow when the temperature exceed $\beta$ transus temperature, these small $\beta$ grains will provide idea nucleation sites, it quickly grows into the melt pool. The growing grain forms as a continuation of another grain in the interface of the substrate. This process is known as epitaxial grain growth. By adding another layer, the $\beta$ grains continue to nucleate and grow from the previous $\beta$ grains. This process could cause a columnar growth as described in Figure 5 and metallurgical observation in Figure 2, Figure 3 and Figure 4, respectively. In order to refine the grain size, it's necessary to increase the heterogeneous nucleation. For this direct laser fabrication, more Ti6A14V powders will be ejected into the melt pool by keeping the laser power constant, reducing the scanning speed and increasing the duration time. So more nucleation sites can block the columnar grain growth, the grains can be refined by reducing the scanning speed and increasing the duration time. Meanwhile, the built height is different for the changes of laser processing parameters. It seems to have decreased slightly with increasing laser power, scanning speed and duration time. The result is convincible because, assuming an excess of power, scanning speed and duration time, more powders will be melted as more energy is absorbed, resulting in thicker and wider layers.

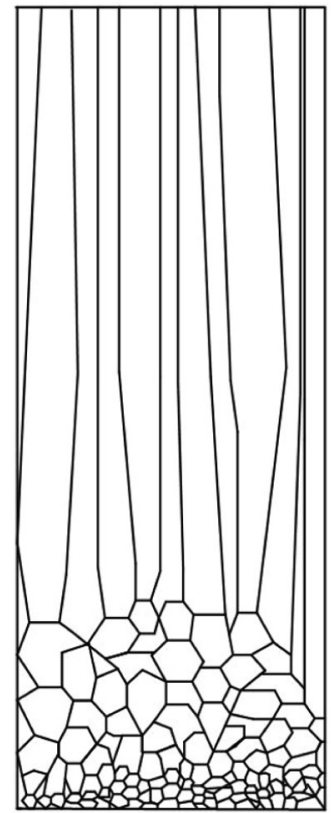

Figure 5. Schematic diagram of epitaxial grain growth of additive deposition of Ti6Al4V sample.

If the melt pool solidifies quickly, the time available for poor spreading would be small. Therefore, a thicker layer and lower height would be obtained. 


\section{Conclusion}

The microstructure of the additive laser fabricated Ti6Al4V affected by pulsed laser parameters has been systematically studied. It was found that the laser power, scanning speed, duration time are sensitive on the grain morphology and the dimension of the specimens. Big columnar grains are rather easy to obtain during the direct laser fabricated Ti6Al4V alloy. By reducing the scanning speed, increasing the duration time and laser power, the big columnar grain growth could be blocked and refined. Meanwhile, cooling rate is an important factor in determining the resultant microstructure and build height of the deposited billets. The build height seems to

\section{References}

1. Baufeld B, Biest OVD and Gault R. Additive manufacturing of Ti6A14V components by shaped metal deposition: microstructure and mechanical properties. Materials \& Design. 2010; 31:s106-s111. http://dx.doi.org/10.1016/j.matdes.2009.11.032.

2. Wu X and Mei J. Near net shape manufacturing of components using direct laser fabrication technology. Journal of Materials Processing Technology. 2003; 135(2-3):266-270. http://dx.doi. org/10.1016/S0924-0136(02)00906-8.

3. Kruth JP, Froyen L, Van Vaerenbergh J, Mercelis P, Rombouts $\mathrm{M}$ and Lauwers B. Selective laser melting of iro-based powder. Journal of Materials Processing Technology. 2004; 149(13):616-622. http://dx.doi.org/10.1016/j.jmatprotec.2003.11.051.

4. Yadroitsev I, Bertrand P and Smurov I. Parametric analysis of the selective laser melting process. Applied Surface Science. 2007; 253(19):8064-8069. http://dx.doi.org/10.1016/j. apsusc.2007.02.088.

5. Rometsch PA, Zhong H, Nairn KM, Jarvis T and Wu X. Characterization of a laser fabricated hypereutectic Al-Sc alloy bar. Scripta Materialia. 2014; 87:13-16. http://dx.doi. org/10.1016/j.scriptamat.2014.05.021. have decreased with increasing laser power, scanning speed and duration time.

\section{Acknowledgements}

We would like to acknowledge the financial support provided by the National Nature Science Foundation of China (Grant No. 51371114 and 51501112), the 973 Program under Grant No. 2012CB619600, the China Postdoctoral Science Foundation (Grant No. 2014M550235 and 2015T80431), the Shanghai Postdoctoral Sustentation Fund (Grant No. 14R21410900) and the fund of National Engineering and Research Center for Commercial Aircraft Manufacturing (Grant No. SAMC14-JS-15-047).

6. Wang F, Mei J and Wu X. Direct laser fabrication of Ti6Al4V/ TiB. Journal of Materials Processing Technology. 2008; 195(13):321-326. http://dx.doi.org/10.1016/j.jmatprotec.2007.05.024.

7. Qiu CL, Ravi GA and Attallah MM. Microstructure control duing direct laser deposition of a $\beta$-titanium alloy. Materials \& Design . 2015; 81:21-30. http://dx.doi.org/10.1016/j.matdes.2015.05.031.

8. Qiu CL, Ravi GA, Dance C, Ranson A, Dilworth S and Attallah MM. Fabrication of large Ti6A14V structures by direct laser deposition. Journal of Alloys and Compounds. 2015; 629:351361. http://dx.doi.org/10.1016/j.jallcom.2014.12.234.

9. Hua T, Jing C, Fengying Z, Xin L and Weidong H. Microstructure and mechanical properties of laser solid formed Ti6Al4V from blended elemental powders. Rare Metal Materials and Engineering. 2009; 38(4):574-578. http://dx.doi.org/10.1016/ S1875-5372(10)60028-8.

10. Tian XJ, Zhang SQ and Wang HM. The influences of anneal temperature and cooling rate on microstructure and tensile properties of laser deposited Ti4A11.5Mn titanium alloy. Journal of Alloys and Compounds. 2014; 608:95-101. http:// dx.doi.org/10.1016/j.jallcom.2014.04.058.

11. Taminger KMB and Hafley RA. RTO-MP-AVT-139 - Cost effective manufacture via net shape processing. In: AVT-139 Specialists' Meeting; 2006; Amsterdam, Netherlands. Amsterdam: NATO Science and Technology Organization; 2006. 264 p. 